\title{
A ARRECADAÇÃo dO IPTU, NO ESTADO DO PARANÁ, NO PERÍODO DE 1997 A 2011: UM OLHAR SOB OS IMPACTOS DA LEI DE RESPONSABILIDADE FISCAL
}

\author{
Rogélio Gerônimo dos Santos ${ }^{1}$ \\ Sidnei Pereira Nascimento ${ }^{2}$
}

\section{Resumo}

O Brasil desponta-se como um dos países com maior carga tributária do mundo. Essa tributação é necessária para fazer frente às despesas com serviços característicos de Estado que são demandados pela sociedade. Entretanto, os impostos que são de competências dos municípios não têm mostrados impactos significativos nas receitas orçamentárias municipais. Dessa forma, o objetivo deste estudo é analisar o comportamento da arrecadação per capita do Imposto referente ao artigo 156, inciso I, da Constituição Federal, o IPTU, no estado do Paraná, no período entre 1997-2011, sob os impactos da Lei de Responsabilidade Fiscal. A distribuição espacial da arrecadação dos tributos municipais é determinada através da utilização de técnicas de Análise Exploratória de Dados Espaciais - teste $I$ de Moran Global e Local - para verificar a autocorrelação espacial entre os municípios do Paraná e confirmar a existência de clusters espaciais. Os resultados demonstram que nos dois períodos, observouse concentração de municípios pertencentes à mesorregião Metropolitana de Curitiba no padrão de agrupamento alto-alto. Todavia, com o advento da LRF a mesorregião Metropolitana de Curitiba não mostrou ser mais eficiente na arrecadação per capita do IPTU no período compreendido entre 2005-2011 comparado a 1997 a 2004.

Palavras-chave: Receitas per capita do IPTU. Lei de Responsabilidade Fiscal. Concentração.

\begin{abstract}
Brazil is coming up as one of the countries with the highest tax burden in the world. Such taxation is necessary to meet the costs of services characteristics of the State that are demanded by society. However, the taxes which are the competence of municipalities have not shown significant impacts on city budget revenues. Thus, the objective of this study is to analysis the behavior of the collection per capita Tax revenues relating to Art. 156, I of the Constitution, the (TPTU), in the state of Paraná, in the period 1997-2011 with the impacts of the Fiscal Responsibility Law (FRL). The spatial distribution of the collection of municipal taxes is determined through the use of techniques of Exploratory Spatial Data Analysis (ESDA) - Index Moran Local and Global - to verify spatial autocorrelation between the municipalities of Parana and confirm the existence of spatial cluster. The results shown that in the two periods, there was concentration of municipalities belong to the mesoregion Metropolitan of Curitiba in the clustering pattern high-high. However, with the advent of the LRF middle the mesoregion Metropolitan of Curitiba has not shown to be more efficient in the collection Tax Property Territorial Urban (TPTU) per capita in the period 2005-2011 compared to 1997-2004.
\end{abstract}

Keywords: Income per capita TPTU. Fiscal Responsibility Law. Concentration.

\footnotetext{
1 Economista e Mestrando em Economia Regional pela Universidade Estadual de Londrina (UEL). Servidor Público Municipal desde 1995 e Professor de Finanças Públicas e Auditoria em Contratos de Licitação para curso de especialização. E-mail: rogelio1974@ sercomtel.com.br

2 Economista Graduado na Universidade Estadual de Londrina (UEL), Mestrado em Economia pela Universidade de Brasília (UNB), Doutor em Economia Aplicada pela ESALQ/USP, Professor da Universidade Estadual de Londrina. E-mail: $\underline{\text { sidnei@uel.br }}$
}

Recebido em: 14/11/2013

Aceito em: 25/06/2014 


\section{INTRODUÇÃO}

A arrecadação de imposto não é um fenômeno brasileiro tampouco fato recente. A história mostra que relatos que cerca de 3000 a.C, na Mesopotâmia, os reis já cobravam impostos de seus súditos. Fatos estes que passaram pelos assírios, babilônios, romanos, ultrapassou a idade média, as revoluções americana e francesa e chegaram aos dias atuais (CUNHA, 2002).

No Brasil, os primeiros relatos de tributação ocorreram no período chamado Capitanias Hereditárias, compreendido entre os anos de 1532 a 1548. Posteriormente, foi aperfeiçoando o arcabouço jurídico, a fim de auferir uma arrecadação de impostos de maneira mais eficiente. Com as transformações ocorridas no Brasil, a partir da década de 1960, observa-se incipiente descentralização da arrecadação tributária. Isso foi consolidado com a Constituição de 1988, que outorgou maiores poderes aos estados e municípios de legislar sobre o tema (PRADO JUNIOR, 2004).

Esses recursos financeiros, frutos da arrecadação tributária, têm como finalidade garantir a oferta de serviços à população. Segundo Riani (1997), os gastos públicos são escolhas políticas dos governos no que se refere aos serviços que são prestados à sociedade. Giambiagi e Além (2000) observa que os administradores públicos, ao fazerem suas escolhas, deixarão alguns grupos insatisfeitos.

Dessa forma, os recursos oriundos dos impostos tem a finalidade, dentre outras, de preencher as lacunas das falhas de mercados. Assim, os desafios dos gestores públicos são de minimizar os impactos negativos, buscando o máximo de eficiência entre os agentes financiadores e os que necessitam desses serviços ofertados pelo Estado (PINDYCK; RUBINFELD, 2006).

Os impostos típicos de municípios são: Imposto Predial Territorial e Urbano (IPTU), Imposto Sobre Transmissão de Bens Imóveis (ITBI) e o Imposto Sobre Serviços de Qualquer Natureza (ISSQN). O IPTU, objeto de estudo deste artigo, foi delegado aos municípios, através do art. 156, inciso I, da Constituição Federal de 1988, tem como fato gerador a propriedade imobiliária.

No Paraná, os municípios ao longo dos anos, vêm perdendo participação das receitas oriundas dos impostos típicos de sua competência em relação às receitas orçamentárias. No triênio 2000-2002 essas receitas representavam 12,25\% e alcançou 12,90\%, no triênio 2003-2005. No triênio 2006-2008 houve recuo para 12,74\% e chegou-se a 9,15\%, no triênio 2009-2011 (SANTOS et al, 2013). 
Assim, com o advento da Lei de Responsabilidade Fiscal (LRF) que impôs aos agentes públicos, dentre outras, melhor gestão nas arrecadações dos impostos, o problema da pesquisa diz respeito se no período de $2005-2011^{3}$ ocorreram aumentos nas receitas oriundas do IPTU, comparadas ao período 1997-2004.

Nesse contexto, o objetivo deste artigo é analisar o comportamento da arrecadação do IPTU no estado em dois períodos: 1997-2004 e 2005-2011, sob os impactos da Lei de Responsabilidade Fiscal. A metodologia utilizada para identificar o padrão espacial desse imposto será determinada através de utilização de técnicas de Análise Exploratória de Dados Espaciais (AEDE) que tem como ferramenta o teste $I$ de Moran Global e Local.

A hipótese deste estudo é que com advento da Lei de Responsabilidade Fiscal (LRF) houve um aumento da arrecadação do IPTU no estado, ou seja, no período referente à 2005-2011 quando comparada com o período de 1997 a 2004, principalmente por mesorregiões compostas por municípios com maiores número populacional.

Além da introdução, este artigo está estruturado em quatro partes, da seguinte forma: uma breve revisão da literatura; metodologia; descrição e análise dos resultados; e, por fim, as considerações finais.

Destaca-se a importância deste estudo no segmento ligado às finanças públicas que tem relevância e interesse socioeconômico, visto que os investimentos com recursos financeiros oriundos do IPTU são de grande importância para o crescimento e desenvolvimento dos municípios. Dessa forma, este estudo corrobora no entendimento do processo de arrecadação do IPTU que oferece subsídios para planejar políticas governamentais, que vise melhorarias na arrecadação tributária municipal do estado do Paraná e para os demais estados confederados.

\section{UMA BREVE REVISÃO DA LITERATURA}

O presente capítulo apresenta uma breve revisão da literatura. Todavia antes se apresentar o subcapítulo 2.1, 2.2 e 2.3, o estudo merece apresentar algumas características do estado do Paraná.

O Paraná faz fronteira a noroeste com o estado do Mato Grosso. Ao norte e nordeste com o estado de São Paulo. Ao sul com o estado de Santa Catarina. À leste é

\footnotetext{
${ }^{3}$ O período foi divido em dois - 1997-2004 e 2005-2011, visto que em 2005 iniciou-se a primeira gestão municipal com os três instrumentos de planejamento financeiro da administração pública nos em consonância com a Lei de Responsabilidade Fiscal (LRF). Esses instrumentos são: Plano Plurianual (PPA); Lei de Diretrizes Orçamentárias (LDO) e Lei de Orçamento Anual (LOA). Ver com detalhes no subcapítulo 2.2 - Lei de Responsabilidade Fiscal e os Instrumentos de Planejamento Financeiro.
} 
banhado pelo Oceano Atlântico. Na região sudoeste faz fronteira com a Argentina e a oeste com o Paraguai (IBGE, 2014).

Com 399 municípios o estado do Paraná é formado por uma área de aproximadamente 200 mil quilômetros quadrados. Em 2013 apresentou uma população estimada de 10,9 milhões habitantes, com densidade demográfica de 52,40 $\mathrm{Hab} / \mathrm{Km}^{2}$ (IBGE, 2014).

O Índice de Desenvolvimento Humano Municipal (IDHM), nos anos de 1991, 2000 e 2010 correspondeu respectivamente a 0,507, 0,650 e 0,749. Isto equivale uma variação positiva de 47,73\% entre os anos de 1991 e 2010 (IBGE, 2014).

Em 2009, as receitas orçamentárias realizadas alcançaram $\mathrm{R} \$ 15,5$ bilhões, sendo as receitas tributárias no montante de 2,7 bilhões, que correspondem a $17,42 \%$ de toda a arrecadação no estado do Paraná (IBGE, 2014).

Em 2011, o Paraná, possuía 3.977 empresas ativas na construção civil que empregou 123 mil pessoas. Apresentou também, em 2011, aproximadamente 142,7 mil unidades de revenda comercial, que empregava aproximadamente 748,6 mil pessoas. No setor de serviços o numero de empresas alcançou 89,8 mil unidades, ocupando 655,5 mil pessoas. E por fim, o setor industrial alcançou 17,5 mil unidades industriais, com 657,6 mil pessoas ocupadas (IBGE, 2014).

A Figura 1 exibe a localização das dez mesorregiões ${ }^{4}$ do estado do Paraná. Além das dez mesorregiões, também são divididas em trinta e nove microrregiões ${ }^{5}$. As mesorregiões são denominadas conforme descritas a seguir: mesorregião Noroeste (1); mesorregião Centro Ocidental (2); mesorregião Norte Central (3); mesorregião Norte Pioneiro (4); mesorregião Centro Oriental (5); mesorregião Oeste (6); mesorregião Sudoeste (7); mesorregião Centro Sul (8); mesorregião Sudeste (9); e mesorregião Metropolitana de Curitiba (10) (IPARDES, 2012).

\footnotetext{
${ }^{4}$ Mesorregião é uma subdivisão dos estados brasileiros que abrange diversos municípios de uma área geográfica, que por sua vez, são subdivididas em microrregiões. Foi criada pelo Instituto Brasileiro de Geografia e Estatística (IBGE) para fins estatísticos e não constitui uma entidade política ou administrativa.

${ }^{5}$ Paranavaí (1); Umuarama (2); Cianorte (3); Goioerê (4); Campo Mourão (5); Astorga (6); Porecatu (7); Florai (8); Maringá (9); Apucarana (10); Londrina (11); Faxinal (12); Ivaiporã (13); Assaí (14); Cornélio Procópio (15); Jacarezinho (16); Ibaiti (17); Wenceslau Braz (18); Telêmaco Borba (19); Jaguaraíva (20); Ponta Grossa (21); Toledo (22); Cascavel (23); Foz do Iguaçu (24); Capanema (25); Francisco Beltrão (26); Pato Branco (27); Pitanga (28); Guarapuava (29); Palmas (30); Prudentópolis (31); Irati (32); Vitória (33); São Mateus do Sul (34); Cerro Azul (35); Lapa (36); Curitiba (37); Paranaguá (38); e Rio Negro (39).
} 
Figura 1 - Mapa das mesorregiões do estado do Paraná.

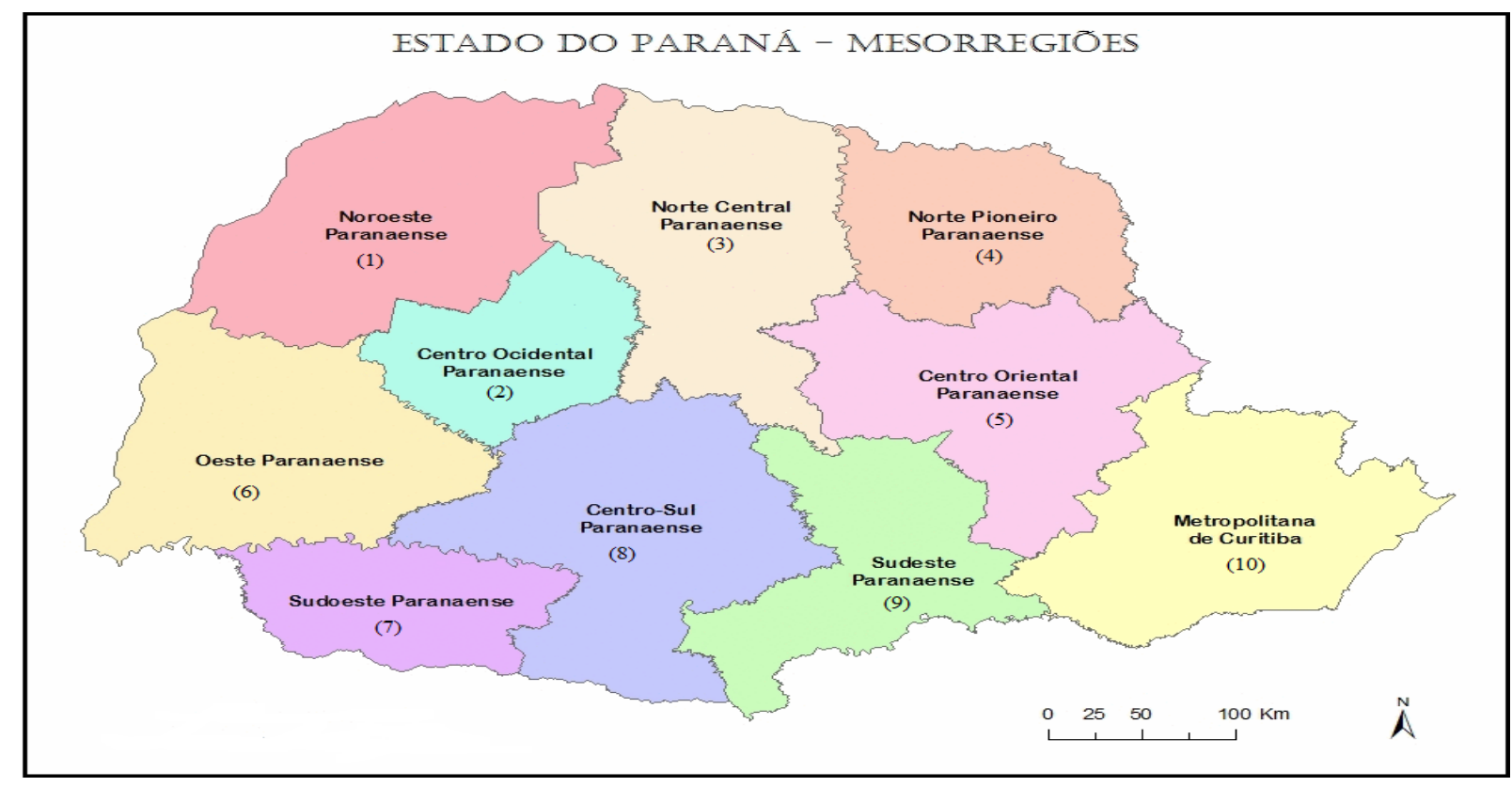

Fonte: www.baixarmapas.com.br, alterado pelos Autores com auxílio do software Paint.

\subsection{Imposto Predial e Territorial Urbano}

Oliveira (2009) observa que, no Brasil, o IPTU figurava na primeira Constituição Republicana, de 1891, como um imposto de competência estadual . Todavia, essa outorga aos estados foi transferida aos municípios pela Constituição de 1934, permanecendo até os dias atuais. A sua origem dividia-se em dois tributos distintos - o imposto predial e o imposto territorial - com a unificação ocorrendo apenas com o advento da Constituição de 1946 (MACHADO, 2001).

A partir de então não sofreu modificações no que tange a sua competência. Esse imposto, após a Constituição de 1988, foi denominado de Imposto sobre a Propriedade Territorial e Urbana (IPTU), conforme art. 156, inciso I. (SPITZCOVSKY; MOTA, 2008).

A base de cálculo do IPTU é o valor venal do imóvel conforme aponta o art. 33 do Código Tributário Nacional (CTN). Vale salientar, conforme adverte Andrade (2009), o Propriedade Territorial e Urbana (IPTU) a partir da Emenda Constitucional 29/2000, que admite de forma expressa, a progressividade do imposto em função do valor do imóvel bem como a diferenciação de alíquotas e razão da localização e do uso conferido à propriedade. Ressalta-se que não há alíquota máxima para cobrança do Propriedade Territorial e Urbana (IPTU). Entretanto é vedada a utilização do tributo com efeito de confisco, conforme versa o art. 150, inciso IV, da Constituição vigente. 
A Constituição de 1988 no art. 182, inciso II, § $4^{\circ}$ permite a utilização, pelos municípios, de alíquotas para imóveis em desacordo com o plano diretor urbano com a finalidade de desestimular conduta errônea do solo urbano. Nesse caso específico o imposto tem o caráter extrafiscal.

O Código Tributário Nacional, no caput do art. 32, define como fato gerador do Imposto sobre Propriedade e Territorial Urbana (IPTU), a propriedade, o domínio ou a posse do bem imóvel por natureza ou por acessão física. Entretanto, Giacomini (2010, apud Alexandre 2008) adverte que existe uma diferença do texto Constitucional com o que descreve o Código Tributário Nacional (CTN), pois naquela norma rege que o imposto incide sobre a propriedade, enquanto o CTN descreve como fato gerador sobre a propriedade, o domínio útil ou a posse.

Ainda, nesse sentido Oliveira (2009) observa que além da responsabilidade do pagamento do Imposto sobre Propriedade Predial e Territorial Urbana (IPTU), adquirido pelo proprietário do bem imóvel, leis municipais poderá atribuir a terceiros a obrigação de recolher o imposto, à fazenda pública municipal, solidariamente ou subsidiariamente.

O aspecto espacial para ocorrer incidência do imposto, o imóvel deve estar localizado na área urbana do município. Assim, estão excluídos do fato gerador do Imposto sobre Propriedade Predial e Territorial Urbana (IPTU), os terrenos e prédios situados nas zonas rurais, cujas propriedades estão sujeitas à cobrança do Imposto Territorial Rural (ITR), que compete à União (ATALIBA, 1996).

Para impedir conflitos de competências, o inciso I do artigo 146 da Constituição de 1988 estabelece caber à lei complementar dispor sobre conflitos de competência entre os entes públicos no que tange ao assunto tributário. Dessa forma, o CTN tem força de lei complementar e cumpre o papel constitucional quando define que uma área para ser considerada urbana deve possuir pelo menos dois dos melhoramentos relacionados a seguir: a) meio-fio ou calçamento, com canalização de aguas pluviais; b) sistema de abastecimento de água; c) sistema de esgoto sanitário; d) escola primária ou posto de saúde a uma distância máxima de três quilômetros do imóvel considerado.

Ainda deve ser observados pelos agentes públicos sobre as atualizações da planta genérica de valores que servem como critérios de método de avaliação para estabelecer o valor venal dos imóveis a serem tributados. É na planta genérica de valores que está definida a valoração dos imóveis de cada logradouro do município. O grande problema das cidades brasileiras, com raras exceções, que os valores das plantas estão abaixo do valor de mercado, 
influenciando diretamente nas receitas oriundas do Imposto sobre Propriedade Predial e Territorial Urbana (IPTU).

\subsection{Lei de Responsabilidade Fiscal e os Instrumentos de Planejamento Financeiro}

A Lei Complementar 101/2000, conhecida por Lei de Responsabilidade Fiscal (LRF), tem como objetivo estabelecer normas de finanças públicas voltadas para responsabilidades na gestão fiscal.

A gestão fiscal implica na ação planejada e clara em que se antecipam os riscos e ajustam anormalidades capazes de afetar o equilíbrio das finanças públicas, mediante cumprimento de metas pré-estabelecidas nos instrumentos de planejamento financeiro entre receitas e despesas e à obediência aos limites e condições no que tange a renúncia de receitas.

Lino (2001) observa que com o advento da Lei de Responsabilidade Fiscal (LRF) o modelo de gestão da "máquina pública" pautada no welfare state deveria ser definitivamente encerrado. Dias (2009) argumenta que a forma intervencionista na gestão pública fundamentada na teoria econômica Keynesiana deveria ser substituída pela corrente neoliberal. Dessa forma, o governo federal buscou executar, principalmente no período entre 1994-2002, uma política econômica pautada na austeridade fiscal, seguindo a "cartilha" de normas financeiras do Fundo Monetário Internacional (FMI).

Nesse contexto, em 2005 foram empossados os prefeitos para a primeira gestão com os três instrumentos de planejamento financeiro nas normas estabelecidas pela Lei de Responsabilidade Fiscal (LRF). Diferente do cenário de seus antecessores, empossados em 2001, que assumiram suas respectivas administrações com esses instrumentos já elaborados pelo Executivo e aprovados pelo Legislativo, sem as exigências previstas na Lei de Responsabilidade Fiscal (LRF). Isso foi o principal motivo para escolha do início do segundo período ser o ano de 2005.

Conforme observa Andrade (2006) que o processo de planejamento público inicia-se com o Plano Diretor ${ }^{6}$. Todavia, na área financeira ${ }^{7}$ os três instrumentos de planejamento são: O Plano Plurianual (PPA); Lei de Diretrizes Orçamentárias (LDO) e a Lei de Orçamento Anual (LOA). Esses instrumentos levam à eficiência na gestão da "máquina pública" e foram ratificados a sua importância com a LRF, dando ênfase no controle e transparência das finanças e na responsabilização dos gestores.

\footnotetext{
${ }^{6}$ O Plano Diretor é exigido apenas dos munícipios com mais de 20 mil habitantes.

${ }^{7}$ O PPA, LDO e a LOA são instrumentos de planejamento financeiros para todos os municípios.
} 
O Plano Plurianual (PPA) expressa o planejamento e tem como finalidade principal conduzir os gastos públicos de forma racional. Sua importância reside no fato de dar as diretrizes aos governos quanto à realização de despesas de capital além dos programas de natureza continuada: coleta de lixo, segurança, saúde, educação, dentre outros.

A Lei de Diretrizes Orçamentárias (LDO) introduzida no Direito Financeiro pela Constituição de 1988 faz o elo entre o Plano Plurianual (PPA) e a Lei de Orçamento Anual (LOA). Em outras palavras, a Lei de Diretrizes Orçamentárias (LDO) prioriza as principais metas estabelecidas no Plano Plurianual (PPA) para serem executadas no orçamento anual. A Lei de Diretrizes Orçamentárias (LDO) deverá além de definir as prioridades e nortear a elaboração da Lei de Orçamento Anual (LOA), também dispõem sobre políticas de pessoal e as alterações na legislação tributária. Dessa forma, quando a Administração pretende alterar a norma tributária do exercício seguinte, deverá indicar as intenções na Lei de Diretrizes Orçamentárias (LDO), pois acarretam reflexos no total de recursos financeiros com os quais o poder público poderá contar no ano seguinte (ANDRADE, 2006).

A Lei de Orçamento Anual (LOA) revestida por atos formais prevê as receitas e fixa as despesas que serão realizadas no período de um ano, sendo facultado aos agentes públicos realizar as despesas que na Lei de Orçamento Anual (LOA) estão fixadas, sem temer sanções administrativas ou judiciais. Por isso é chamada de lei autorizativa e não impositiva (ANDRADE, 2006).

Como ressalta Andrade (2002) a Lei de Orçamento Anual (LOA) é a materialização do planejamento que expressa seus programas de atuação, discriminando a origem e o montante dos recursos, bem como a natureza e o montante das despesas a serem efetuadas.

Também influenciou na escolha do ano, o fato de que os mecanismos de controle mais efetivos das contas municipais ocorreram a partir de 2005 através do Tribunal de Contas do estado do Paraná (TCE-PR), mesmo que o principal instrumento para esse fim, o SIM$\mathrm{AM}^{8}$ tenha sido implantado no exercício financeiro de 2002.

\subsection{Lei de Responsabilidade Fiscal e a Renúncia Fiscal}

A Lei Responsabilidade Fiscal (LRF) compreende como renúncia de receitas: anistia, subsídios, crédito presumido, concessão de isenção em caráter não geral, alteração de

\footnotetext{
${ }^{8}$ Sistema de Informações Municipais implantado inicialmente, em 2002, com ideia inicial de coletar dados que nos anos seguintes de forma gradativa recebeu funções preventivas e regulatórias, tornando assim, mais eficiente no controle das receitas e despesas municipais.
} 
alíquota ou modificação de base de cálculo que implique redução discriminada de tributos ou condições, e outros benefícios que correspondam a tratamento diferenciado ( $\S 1^{\circ}$ do art. 14 da LRF). Também, trata-se da renúncia fiscal o $§ 6^{\circ}$ do art. 165 da Constituição Federal.

$\mathrm{Na}$ ótica de Villela (2013) renúncia é o ato de uma alteração na alíquota, redução da base de cálculo, quaisquer outras regras especiais que resultem em montante de obrigação tributária inferior à regra normal. Villela (2013) continua a definir como renúncia de receita a abdicação do Fisco de recolher tributos com interesse de incentivar ou favorecer determinado setores, atividades, regiões ou agentes econômicos.

Para Nunes (2013) a renúncia de receita é uma das variáveis que extrapola a fronteira do tempo e do objeto da Lei de Orçamento Anual (LOA). Isso é bem definido no artigo $5^{\circ}$, inciso II da Lei de Responsabilidade Fiscal (LRF) que descreve que o projeto da lei orçamentária será acompanhado de documentos, dentre outros, a que se refere à renúncia fiscal.

A Lei de Responsabilidade Fiscal (LRF) reserva a seção II do capítulo III às questões relacionadas à renúncia fiscal. No caput do artigo 14 a lei observa que os benefícios ou incentivo tributários que acarretarão em renúncia de receita deverão estar acompanhados de relatório estatístico do impacto orçamentário e financeiro no exercício da vigência e nos dois anos subsequentes. Os incisos I e II do art. 14 requer do proponente demonstração que a renúncia das receitas não afetará as metas e resultados ou que apresente medidas de compensação, sendo indispensável para concessão de renúncia da receita.

Todavia, Afonso (2013) observa que a renúncia fiscal, por princípio, deve ser tratada no sentido mais amplo como uma forma de despesa aplicada mesmo quando a receita inexistia. Nessa ótica, com a data máxima vênia ao saudoso jurista Hely Lopes Meirelles que disse: "A Administração Pública só pode fazer o que a lei permite" (DI PIETRO, 2000, p. 68). E também não violando ao que expressa o inciso II do artigo $5^{\circ}$ da Constituição Federal que "ninguém é obrigado a fazer ou deixar de fazer alguma coisa senão em virtude de Lei" (DANTAS, 2011, p.130), vale ressaltar que à luz dos princípios do direito a renúncia fiscal ultrapassa o princípio da legalidade, pois como observou Afonso (2013) essa matéria deve ser tratada no sentido mais amplo. Ou seja, a inércia do executivo e do legislativo ${ }^{9}$ de não

\footnotetext{
${ }^{9}$ Nesse cenário não cabe referir-se apenas à inércia do executivo, pois as possibilidades de aumento de receitas através de instituição de impostos, mudanças na base de cálculo, atualização na planta genérica de valores e mudanças nas alíquotas, dentre outras, deverão ser submetida para apreciação do legislativo. Todavia, em se tratando de matéria financeira deverá o projeto de lei ser de iniciativa do poder executivo, sendo sujeito a vício insanável que poderá resultar em uma Ação Direta de Inconstitucionalidade (ADIN) que tornará a Lei nula por um tribunal. Não existe no Brasil ainda um consenso jurídico de competência de julgamento das ADINs
} 
instituir, cobrar, ou deixar de atualizar valores a planta geral de valores que implica em menores receitas ao Ente público fica configurada a renuncia de receita.

\section{METODOLOGIA}

As variáveis usadas nesta pesquisa, no período compreendido entre os anos de 1997 a 2011 tiveram como fonte de informações a Secretaria do Tesouro Nacional (STN), onde foram coletados dados referentes aos 399 municípios do estado do Paraná, atualizado pelo Índice de Preços ao Consumidor Amplo (IPC-A) a valores de 2011.

Para atender o objetivo desse estudo será empregada a Análise Exploratória de Dados Espacial (AEDE), através do Índice de Moran Local e Global que mostrará a existência de autocorrelação e formação de clusters espaciais, com auxílio do software Geodata Analysys (GeoDa).

Almeida (2004) explica que a Análise Exploratória de Dados Espaciais (AEDE) versa em um arcabouço de métodos, contendo elementos geográficos que permitem o descobrimento de padrões espaciais nos dados. Anselin (2005) descreve a Análise Exploratória de Dados Espaciais (AEDE) fundamentada nos efeitos decorrentes da dependência e da heterogeneidade espacial. Essa análise tem como finalidade demonstrar a associação de clusters espaciais, averiguar a existência de distintos regimes espaciais ou nãoestacionariedade e identificar observações discrepantes.

Apesar de ser escassos estudos na literatura nacional que analisam a arrecadação do Imposto sobre Propriedade Predial e Territorial Urbana (IPTU) através desta metodologia existem diversos estudos em outros segmentos que utilizam esta técnica para a identificação de clusters espaciais.

A variável avaliada é a arrecadação per capita do Imposto sobre Propriedade Predial e Territorial Urbana (IPTU) dividida pela população, nos períodos compreendidos entre 1997-2004 e 2005-2011. Dessa forma, é possível mensurar a evolução e o padrão locacional dos municípios paranaense nos dois períodos distintos.

\subsection{Determinação da Matriz de Pesos Espaciais}

Para Ribeiro (2010) a dependência ou a autocorrelação espacial denota que a estimação de uma variável de interesse numa certa região ou município depende do valor 
dessa variável nas regiões vizinhas, que formam uma matriz. A vinculação espacial mostra a existência de uma afinidade funcional entre o que ocorre em determinado lugar e o que ocorre em outro local. Dessa forma, diz-se que uma variável de certa região ou município depende desta mesma variável nas regiões ou município vizinhos.

Uma matriz de pesos espaciais busca condensar certo arranjo espacial de influência mútua resultantes do elemento a ser observado que não precisa adotar um enfoque apenas geográfico. Os dados da matriz de pesos espaciais são não estocásticos e exógenos ao modelo, e de forma genérica, são fundamentadas nos arranjos geográficos das observações ou na adjacência entre elas.

A matriz de pesos espaciais é empregada com a finalidade de enlaçar os resultados de contiguidade e imediação sobre os elementos pelo meio de ponderações, ou seja, a variável analisada em cada município recebe uma avaliação quando fizer vizinhança com o município analisado (ALMEIDA, 2004).

No entanto, conforme observa Pimentel e Haddad (2004), têm-se diferentes tipos de matriz de pesos espaciais, quais sejam: Matriz Binária, Distância Inversa, Matriz de Pesos Espaciais Gerais de Cliff e Ord, Matriz de Distância Socioeconômica. Convenciona-se que a matriz de pesos espaciais adotada neste estudo recebe o nome de Queen, onde M1 representa o município central e M2 a M9 os municípios periféricos, conforme Figura 2. A matriz do tipo Queen considera todas as regiões com fronteiras diferentes de zero, incluindo os vértices.

Figura 2 - Matriz de peso espacial - Queen

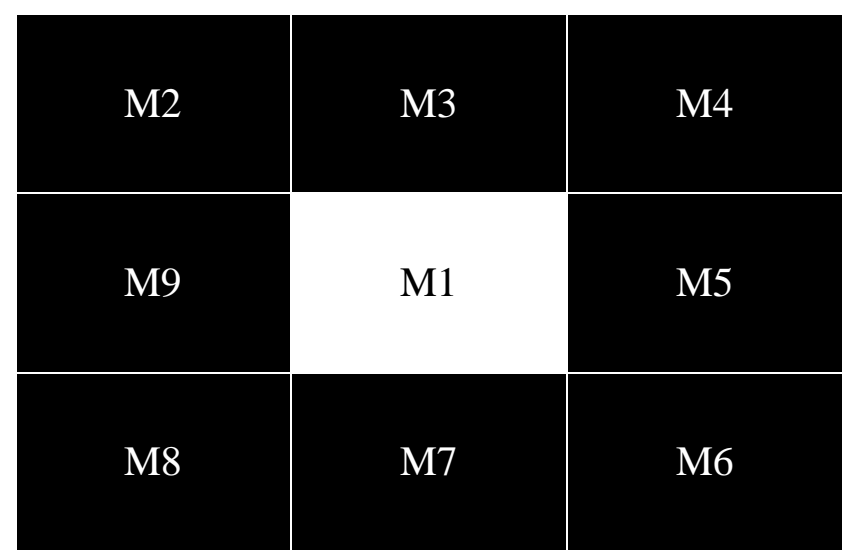

Fonte: Elaborado pelos Autores.

Após a construção da matriz de pesos espaciais, executa-se o processo de obtenção do Índice de Moran Global, como grau de correlação espacial da variável de interesse que será analisado metodologicamente, nos subitens: 3.2 e 3.3. 


\subsection{Estatística I de Moran Global - Univariada}

Segundo Teixeira et al (2009), a estatística I de Moran é o coeficiente que mede a autocorrelação espacial. Ela testa a hipótese de que os dados espaciais estejam disseminados aleatoriamente. A autocorrelação espacial depende da definição do arranjo espacial das observações, expressa pela matriz de pesos espaciais.

Almeida (2004) demonstra a fórmula estatística do I de Moran conforme segue a equação 1:

$$
I=\frac{n}{\sum \sum w_{i j}} \times \frac{\sum \sum w_{i j}\left(y_{i}-\bar{y}\right)\left(y_{j}-\bar{y}\right)}{\sum\left(y_{i}-\bar{y}\right)^{2}}
$$

Em que:

$n$ : é o número de unidades espaciais;

$y_{i}$ : é a variável de interesse;

$w_{i j}$ : é o peso espacial para o par de unidades espaciais $i$ e $j$, medindo o grau de interação entre elas.

A estatística $I$ de Moran tem um valor esperado superior a $-\left[\frac{1}{(n-1)}\right]$, ou seja, mostra o valor que seria obtido se não houvesse padrão espacial nos dados. Dessa forma, os valores de $I$ que excedem indicam autocorrelação espacial positiva. Já os valores de $I$ abaixo do valor esperado iguais a $-\left[\frac{1}{(n-1)}\right]$ indicam autocorrelação negativa. Ao contrário de um coeficiente de correlação, esta estatística não é centrada em zero. À medida que o número de regiões ou município aumenta, o valor esperado da estatística $I$ de Moran aproxima-se de zero. Assim, conclui-se que tal estatística varia entre \pm 1 (ANSELIN, 2005).

A autocorrelação espacial positiva mostra que, alta área de arrecadação per capita do Imposto sobre Propriedade Predial e Territorial Urbana (IPTU) de um município ou região tende a ser circulada por área de arrecadação do Imposto sobre Propriedade Predial e Territorial Urbana (IPTU) per capita também alta dos municípios e regiões vizinhas. O inverso também ocorre: uma baixa área de arrecadação per capita do Imposto sobre Propriedade Predial e Territorial Urbana (IPTU) de um município ou região tende a ser 
contornada por área de arrecadação per capita do Imposto sobre Propriedade Predial e Territorial Urbana (IPTU) igualmente baixa dos municípios e regiões contíguas (PIMENTEL; HADDAD, 2004).

O indicativo de autocorrelação espacial negativa indica que existe uma dissimilaridade entre os valores das características avaliadas e da sua localização espacial. Ela denota que uma elevada área de arrecadação per capita do Imposto sobre Propriedade Predial e Territorial Urbana (IPTU) de uma região ou município tende a ser circulada por pequena área de arrecadação per capita do Imposto sobre Propriedade Predial e Territorial Urbana (IPTU) das regiões ou municípios vizinhos (ALMEIDA, 2004).

O diagrama de dispersão de Moran é uma forma alternativa para interpretar a estatística $I$ de Moran. Essa representação mostra a defasagem espacial da variável de interesse no eixo vertical e o valor da variável de interesse no eixo horizontal. A interpretação para esta estatística é dada por quatro tipos de padrões espaciais: alto-alto; alto-baixo; baixobaixo e baixo-alto.

Alto-alto indica regiões com elevados valores para a variável de interesse, sendo vizinhas de regiões com elevados valores para a mesma. O padrão baixo-baixo revela localidades com reduzidos valores para a variável em análise, sendo circundadas por localidades com baixos valores para a mesma. O padrão baixo-alto mostra localidades com baixos valores para a variável investigada, que são vizinhas de regiões com altos valores para a mesma. Por fim, o padrão alto-baixo caracteriza regiões com elevados valores para a variável em estudo, que são ladeadas por outras com baixos valores para a mesma (TEIXEIRA et al, 2009).

\subsection{Estatística I de Moran Local: Univariada}

Para Anselin (2005), o índice $I$ de Moran local aborda um diagnóstico do indicador global de autocorrelação conforme a contribuição local de cada observação em quatro categorias, nas quais cada uma representa um quadrante no diagrama de dispersão de Moran. A explicação do I de Moran local é intuitiva, dando a indicação do grau de agrupamento dos valores similares da região observada, identificando clusters espaciais, estatisticamente significativos.

A estatística $I$ de Moran local tem como finalidade obter os padrões locais de associação linear que sejam significativos, sendo expressa pelas seguintes equações: 


$$
I_{i}=\frac{\left(y_{i}-\bar{y}\right) \sum w_{i j}\left(y_{j}-\bar{y}\right)}{\sum_{i} \frac{\left(y_{i}-\bar{y}\right)^{2}}{n}}
$$

ou,

$$
I_{i}=z_{i} \sum_{j} w_{i j} z_{j}
$$

Em que:

$z_{i}$ e $z_{j}$ são variáveis padronizadas e a somatória sobre $j$ é tal que somente os valores dos vizinhos $j$ são incluídos $j i$. O conjunto $j i$ abrange os vizinhos da observação $i$, e por definição $w_{i j}=0$.

As avaliações de autocorrelação espacial local devem ser empregadas a fim de indicar a ocorrência de clusters espaciais locais, de valores altos ou baixos, e quais são as regiões que cooperam mais expressivamente para acontecimentos de autocorrelação espacial. Tais conceitos de autocorrelação local são mostrados pelo diagrama de dispersão de Moran e pelas estatísticas de Indicadores Locais de Associação Espacial (LISA) (PEROBELLI; FERREIRA; ALMEIDA, 2008).

\section{DESCRIÇÃO E ANÁLISE DOS RESULTADOS}

Neste capítulo será realizada a descrição e a análise dos resultados obtidos através da Análise Exploratória de Dados Espaciais (AEDE) por meio do Índice de Moran Local e Global, bem como os mapas de significâncias e os mapas de cluster do Imposto sobre Propriedade Predial e Territorial Urbana (IPTU).

Os resultados obtidos da variável de estudo mostram o $I$ de Moran esperado expresso por, $\mathrm{E}(I)=-\left[\frac{1}{(n-1)}\right]$, e fornece o valor que seria obtido se não houvesse padrão espacial nos dados, nesse caso $\mathrm{E}(I)=-0,0025$, onde o valor de $n$ corresponde ao número de municípios do estado do Paraná, num total 399 (IBGE, 2012). Vale ressaltar, que os valores de $I$ esperado acima de $-0,0025$ indicam autocorrelação espacial positiva e os valores abaixo, autocorrelação negativa.

Os resultados da Tabela 1 exibem os valores de I de Moran para a variável arrecadação per capita média das receitas oriundas do Imposto sobre Propriedade Predial e Territorial Urbana (IPTU) para a matriz de pesos espaciais do tipo Rainha (Queen). Os dados 
revelam que existe autocorrelação espacial positiva entre os municípios, já que o valor de $I$ de Moran calculado está acima do valor esperado, considerando uma significância estatística de $5 \%$. Entretanto, a análise da estatística $I$ de Moran a respeito da ocorrência de regimes espaciais, não torna provável a visualização de onde estão esses regimes e a sua evolução ao longo do tempo. Para esta tarefa será utilizado o diagrama de dispersão de Moran. Observa-se que a pseudo-significância empírica dos resultados da Tabela 1 é baseada em 999 permutações aleatórias.

Com relação às variáveis do eixo $x$, segue a definição: IPTU_1P corresponde à média per capita do primeiro período, compreendido entre os anos de 1997 a 2004 da arrecadação do Imposto sobre Propriedade Predial e Territorial Urbana (IPTU); IPTU2P corresponde à média per capita do segundo período entre os anos de 2005 a 2011 da arrecadação do Imposto sobre Propriedade Predial e Territorial Urbana (IPTU).

Tabela 1 - Estatística I de Moran da variável IPTU nos períodos: 1997 a 2004 e 2005-2011.

\begin{tabular}{l|l|l|l}
\hline Variável & Convenção & $\boldsymbol{I}$ & Probabilidade \\
\hline IPTU_1P & \multirow{2}{*}{ Rainha (Queen) } & 0,4712 & 0,05 \\
IPTU_2P & & 0,4166 & 0,05 \\
\hline
\end{tabular}

Fonte: Elaborado pelos Autores, com auxílio do Software Geoda.

Seguem, ainda, as definições das variáveis do eixo y dos diagramas de dispersão de Moran: W_IPTU_IP corresponde à defasagem espacial da média do período de 1997-2004 da arrecadação per capita do Imposto sobre Propriedade Predial e Territorial Urbana (IPTU); W_IPTU_2P corresponde à defasagem espacial da média concernente ao período de 20052011 da arrecadação per capita do Imposto sobre Propriedade Predial e Territorial Urbana (IPTU).

Como já mencionado, o diagrama de dispersão de Moran é dividido em quatro quadrantes, sendo eles: alto-alto; baixo-baixo; alto-baixo e baixo-alto. Os quadrantes mostram a associação local espacial entre os municípios e seus vizinhos.

Conforme mostra a Figura 3 o diagrama de dispersão de Moran é uma ferramenta gráfica para analisar o $I$ de Moran. Para identificar a existência de autocorrelação espacial é indispensável examinar a inclinação da curva mostrada no diagrama de dispersão de Moran. Ou seja, se o coeficiente angular for positivo, apresenta autocorrelação espacial positiva. Se o coeficiente angular for negativo, haverá autocorrelação negativa. Neste caso os coeficientes angulares são positivos, portanto existe correlação espacial positiva para a média dos períodos 1997-2004 e 2005-2011 da arrecadação per capita do Imposto sobre Propriedade Predial e Territorial Urbana (IPTU) dos municípios paranaense. 
Figura 3 - Diagramas de dispersão de Moran da arrecadação média per capita do IPTU.

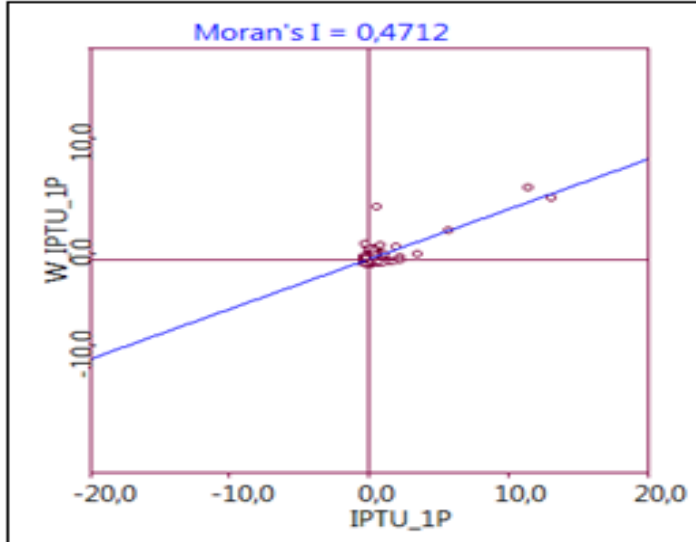

(a) $1997-2004$

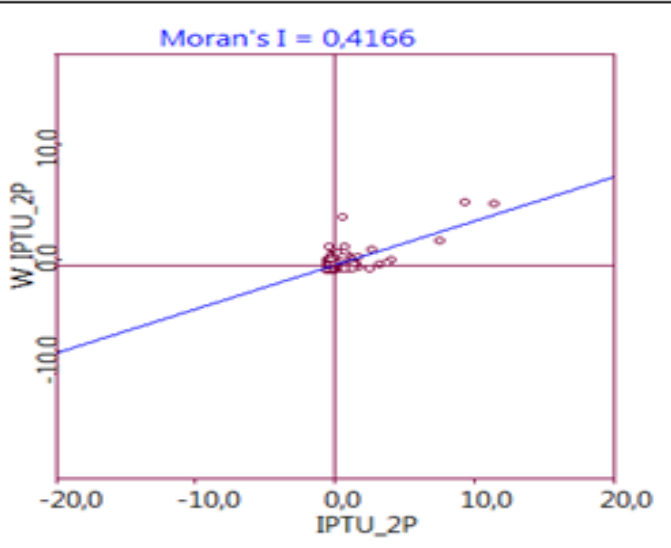

(b) $2005-2011$

Fonte: Elaborado pelos Autores, com auxílio do Software Geoda.

Na ótica de Almeida (2004) a associação linear espacial fornecida pela estatística I de Moran Local pode ser fornecida de forma eficiente através do mapeamento dessas unidades espaciais. A Figura 3 apresenta a significância das unidades espaciais através da estatística I de Moran local para arrecadação média per capita do Imposto sobre Propriedade Predial e Territorial Urbana (IPTU) no estado do Paraná, nos períodos de 1997-2004 e 20052011.

A Figura 4 exibe os clusters significativos para o I local. Almeida (2004) esclarece que o mapa de clusters ilustra as quatro categorias que são estatisticamente significantes, através da combinação do diagrama de dispersão de Moran e o mapa de significância da associação local. Os mapas de clusters mostram o agrupamento dos municípios que apresentam os agrupamentos da arrecadação média per capita do Imposto sobre Propriedade Predial e Territorial Urbana (IPTU).

Figura 4 - Mapas de significância da arrecadação per capita do IPTU dos municípios do estado do Paraná, nos períodos: 1997-2004 e 2005-2011.

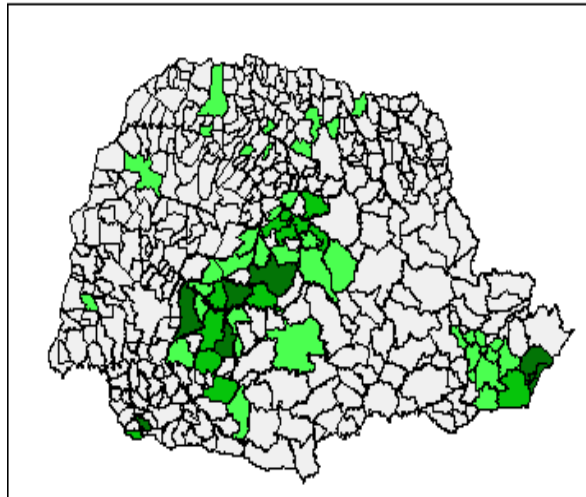

(a) 1997-2004

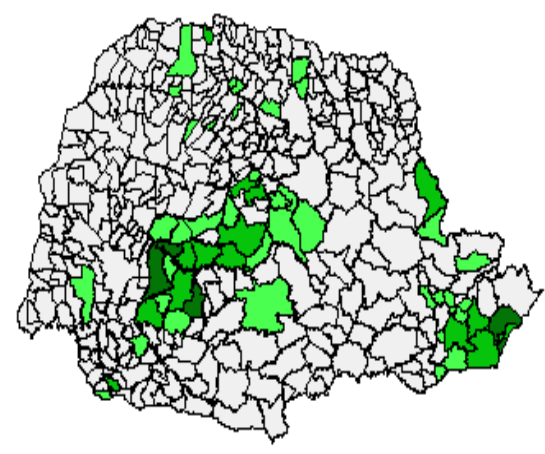

(b) 2005-2011

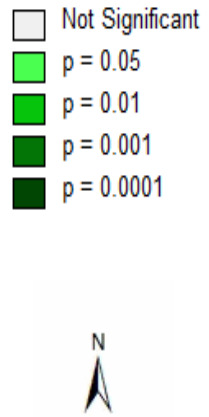

Fonte: Elaborado pelo autor, com auxílio do Software Geoda. 
Nesse sentido, a partir da Figura 5, que demonstra a média dos períodos compreendidos entre 1997 a 2004 e 2005 a 2011 é possível verificar a presença de clusters do tipo alto-alto, principalmente nos municípios pertencentes à mesorregião Metropolitana de Curitiba. Dessa Forma, o mapa (a) da Figura 5 referente ao período de 1997-2004 mostra o agrupamento de cluster tipo alto-alto, com onze ${ }^{10}$ municípios pertencentes à mesorregião Metropolitana de Curitiba. Ainda nesse mesmo padrão de agrupamento, sem a formação de clusters, o mapa (a) da Figura 5 apresenta municípios pertencentes à mesorregião Norte Central $^{11}$.

No cluster de padrão baixo-baixo, o mapa (a) da Figura 5 mostra um agrupamento de trinta e um municípios ${ }^{12}$. Também apresenta no mesmo padrão de agrupamento, sem a formação de cluster municípios da mesorregião Oeste ${ }^{13}$ e Sudoeste $^{14}$. No agrupamento de padrão baixo-alto, do mapa (a) da Figura 5 apresenta apenas um cluster formado por municípios pertencentes à mesorregião Metropolitana de Curitiba ${ }^{15}$. Nesse mesmo agrupamento, o mapa (a) da Figura 5 exibe ainda os municípios na mesorregião Norte Pioneiro $^{16}$, na mesorregião Metropolitana de Curitiba $^{17}$, e na mesorregião Norte Central ${ }^{18}$.

O padrão de agrupamento alto-baixo, do mapa (a) da Figura 5 não mostra formação de cluster, porém, apresenta municípios em várias regiões do estado conforme descrito a seguir: na mesorregião Sudoeste ${ }^{19}$; na mesorregião Centro $\mathrm{Sul}^{20}$; na mesorregião Noroeste ${ }^{21}$.

${ }^{10}$ Colombo, Curitiba, Fazenda Rio Grande, Guaratuba, Matinhos, Paranaguá, Pinhais, Piraquara, Pontal do Paraná, Quatro Barras e São José dos Pinhais.

${ }_{12}^{11}$ Arapongas, Cambé, Iguaraçu, Ibiporã e Paiçandu.

${ }^{12}$ Altamira do Paraná; Borrazópolis; Candido de Abreu; Chopinzinho; Diamante do Sul; Faxinal; Grandes Rios; Guaraniaçu; Iretama; Ivaiporã; Jardim Alegre; Laranjal; Laranjeiras do Sul; Lidianópolis; Lunardelli; Mangueirinha; Manoel Ribas; Marquinho; Nova Cantú; Novas Laranjeiras; Nova Tebas; Palmital; Pitanga; Quedas do Iguaçu; Reserva; Rio Bonito do Iguaçu; Rio Branco do Ivaí; Roncador; Rosário do Ivaí; Santa Maria do Oeste e Virmond.

${ }^{13}$ Diamante D'Oeste.

${ }^{14}$ Salgado Filho.

${ }^{15}$ Almirante Tamandaré e Campo Magro.

${ }^{16}$ Leópolis.

${ }^{17}$ Morretes e Tijucas do Sul.

${ }^{18}$ Sarandi.

${ }^{19}$ Barracão.

${ }^{20}$ Guarapuava.

${ }^{21}$ Paraíso do Norte, Paranavaí e Umuarama. 
Figura 5 - Mapas de clusters da arrecadação per capita média do IPTU dos municípios do estado do Paraná, nos períodos: 1997-2004 e 2005-2011.

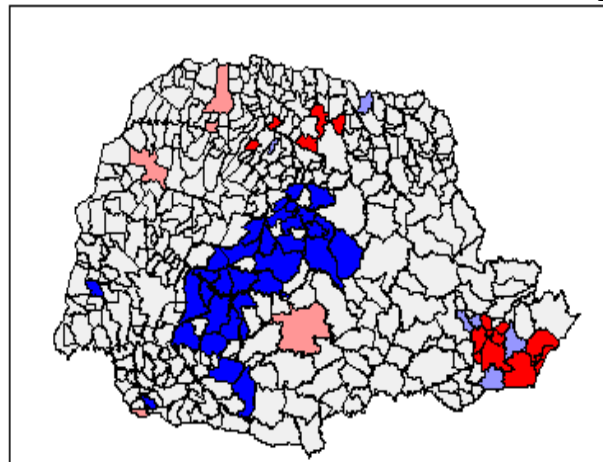

(a) $1997-2004$

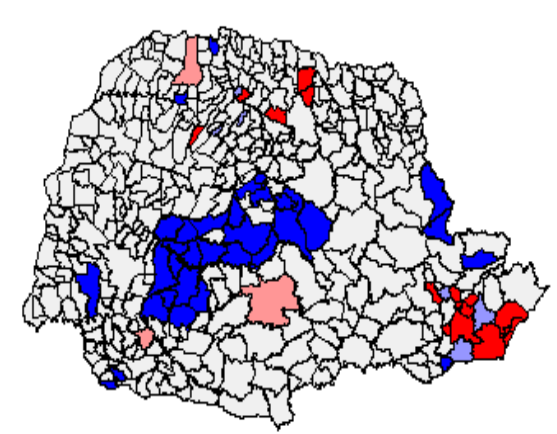

(b) $2005-2011$

Fonte: Elaborado pelos Autores, com auxílio do Software Geoda.

Com relação ao mapa (b) da Figura 5 referente ao período de 2005-2011, o mesmo mostra o agrupamento de dois clusters tipo alto-alto: um cluster formado por dois municípios, pertencentes à mesorregião Norte $\mathrm{Central}^{22}$ e Norte Pioneiro ${ }^{23}$; outro cluster formado por dois municípios pertencentes à mesorregião Metropolitana de Curitiba ${ }^{24}$. Ainda no padrão alto-alto aparecem municípios na mesorregião: Norte $\mathrm{Central}^{25}$; $\mathrm{Noroeste}^{26}$ Metropolitana de Curitiba ${ }^{27}$.

O mapa (b) da Figura 5 exibe três clusters de municípios no agrupamento baixobaixo disperso pelo o estado - um cluster com vinte e quatro municípios ${ }^{28}$, outro com dois municípios pertencentes à mesorregião Sudoeste $^{29}$ e por último um cluster com dois municípios pertencentes à mesorregião Centro Oriental ${ }^{30}$ e Metropolitana de Curitiba ${ }^{31}$. Ainda nesse padrão de agrupamento aparecem sem a formação de clusters na mesorregião Metropolitana de Curitiba ${ }^{32}$, na mesorregião Oeste ${ }^{33}$, na mesorregião Noroeste ${ }^{34}$.

\footnotetext{
${ }^{22}$ Ibiporã.

${ }^{23}$ Sertanópolis.

${ }^{24}$ Colombo, Curitiba, Fazenda Rio Grande, Guaratuba, Matinhos, Paranaguá, Pinhais, Piraquara, Pontal do Paraná, Quatro Barras, São Jose dos Pinhais.

25 Arapongas e Iguaraçu.

${ }^{26}$ Jussara.

${ }^{27}$ Campo Magro.

${ }^{28}$ Altamira do Paraná, Boa Ventura de São Roque, Campina da Lagoa, Cândido de Abreu, Diamante do Sul, Espigão Alto do Iguaçu, Guaraniaçu, Ivaiporã, Jardim Alegre, Laranjal, Laranjeiras do Sul, Lidianópolis, Nova Cantú, Nova Laranjeiras, Nova Tebas, Palmital, Pitanga, Quedas do Iguaçu, Reserva, Rio Branco do Iguaçu, Rio Branco do Ivaí, Roncador e Rosário do Ivaí.

${ }^{29}$ Barracão e Salgado Filho.

${ }^{30}$ Sengês.

${ }^{31}$ Doutor Ulysses.

${ }^{32}$ Agudos do Sul e Tunas do Paraná

${ }^{33}$ Céu Azul.

${ }^{34}$ Inajá e Paraíso do Norte.
} 
O padrão alto-baixo, mapa (b) da Figura 5, exibe uma dispersão no estado no qual compreendem os municípios das mesorregiões: Sudoeste ${ }^{35}$; Centro Sul $^{36}$; Noroeste $^{37}$. Com relação ao padrão baixo-alto o mapa (b) da Figura 5 exibe municípios da mesorregião Metropolitana de Curitiba ${ }^{38}$ e Norte Central ${ }^{39}$.

Diante do exposto, a Análise Exploratória de Dados Espacial (AEDE) evidenciou, que no padrão de agrupamento alto-alto praticamente não houve alteração nos períodos avaliados neste estudo. Sendo que no primeiro período aparece apenas um cluster formado por onze municípios da mesorregião Metropolitana de Curitiba. No mesmo padrão ainda apresenta alguns municípios da mesorregião Norte Central $^{40}$. Para o segundo período aparece a formação de dois clusters: um formado por dois municípios pertencentes às mesorregiões Norte Central $^{41}$ e Norte Pioneiro ${ }^{42}$; outro na mesorregião Metropolitana de Curitiba também com dez municípios ${ }^{43}$ similar ao período de 1997-2004, com destaque que no segundo período não aparece o município de Curitiba. E ainda, no padrão alto-alto aparecem dois municípios na mesorregião Norte Central $^{44}$, um na mesorregião Noroeste ${ }^{45}$ e um município na mesorregião Metropolitana de Curitiba ${ }^{46}$.

Quanto ao padrão baixo-baixo é evidente a redução do número de municípios do segundo período em relação ao primeiro da região que é formada por municípios da região centro sul do estado do Paraná, ou seja, é um "corredor" que se inicia no extremo sul da mesorregião Norte Central e chega até ao extremo sul do estado. Essa faixa de municípios tem um histórico de baixo desenvolvimento econômico e baixo índice de qualidade de vida.

Quando se avalia a participação percentual média das receitas oriundas do Imposto sobre Propriedade Predial e Territorial Urbana (IPTU) no total das arrecadações dos impostos municipais no estado encontra-se uma redução acentuada dessas receitas no segundo período em relação ao primeiro período, conforme ilustra a Figura 6. No período compreendido entre os anos de 1997-2004 as receitas médias anuais do Imposto sobre Propriedade Predial e Territorial Urbana (IPTU) no estado do Paraná correspondiam a

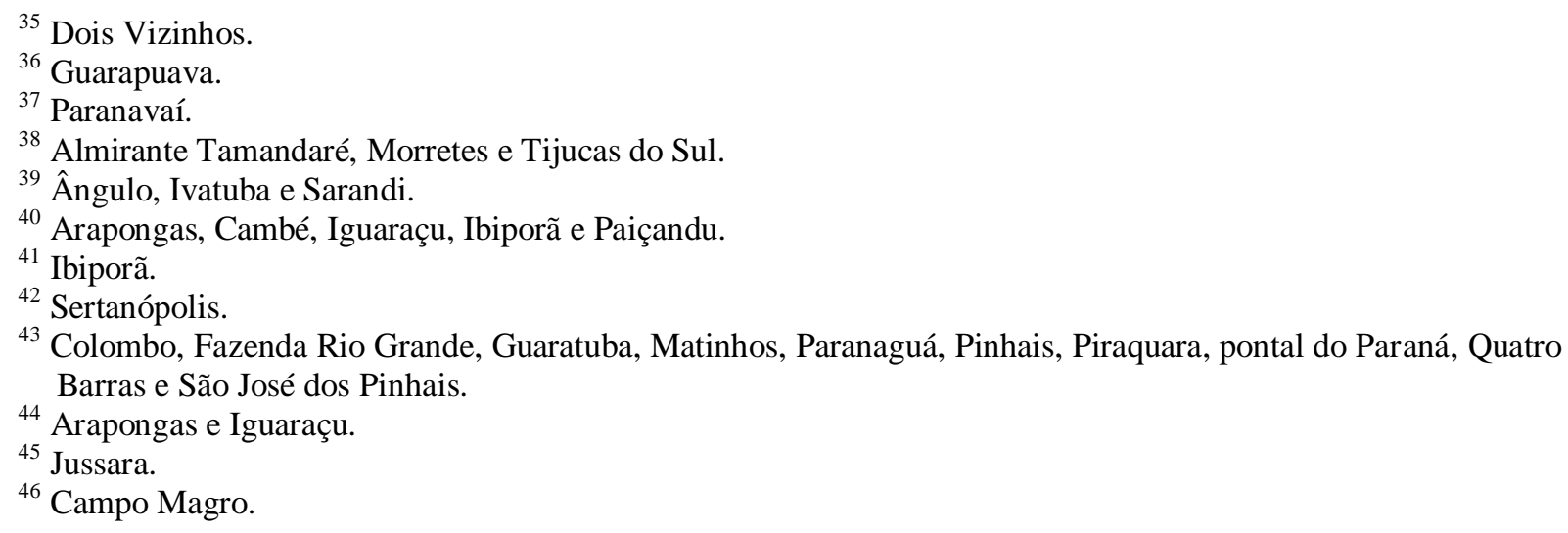


$39,48 \%$ do total arrecadado dos impostos municipais. No segundo período compreendido entre os anos de 2005-2011 passou a 32,80\% que corresponde a uma variação negativa de $16,72 \%$.

Figura 6 - Participação percentual média das receitas oriundas do IPTU no estado do Paraná nos períodos: 1997-2004 e 2005 e 2011.

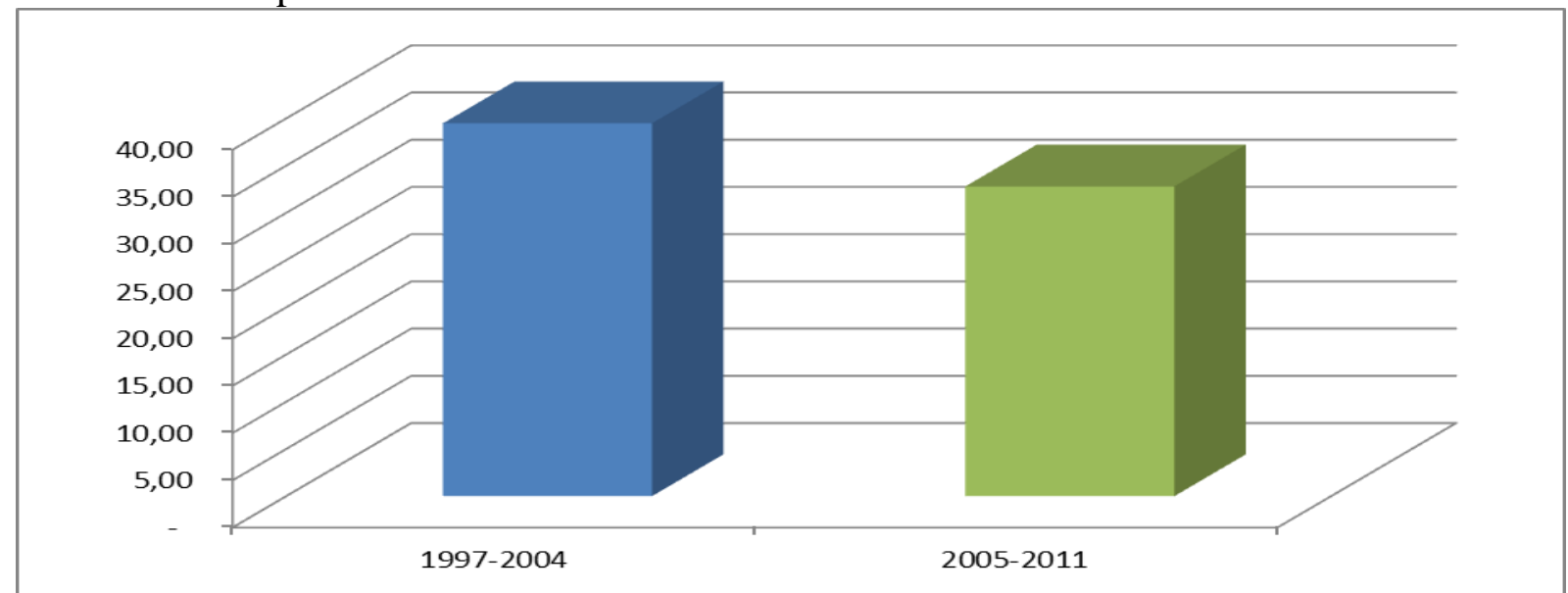

Fonte: Elaborado pelos Autores, com base de dados do STN, $2012^{47}$.

Os resultados mostram retração das receitas oriundas do Imposto sobre Propriedade Predial e Territorial Urbana (IPTU) em relação às demais receitas de impostos municipais, no período de 2005-2011 em relação ao período de 1997-2004 no estado do Paraná.

\section{CONSIDERAÇÕES FINAIS}

O estudo procurou identificar o padrão locacional da arrecadação per capita do Imposto sobre Propriedade Predial e Territorial Urbana (IPTU) para os municípios do estado do Paraná, através da identificação da autocorrelação espacial e detecção de clusters espaciais. Através da utilização da Análise Exploratória de Dados Espaciais (AEDE), foi possível identificar a autocorrelação positiva para a arrecadação per capita do Imposto sobre Propriedade Predial e Territorial Urbana (IPTU) estado do Paraná em dois períodos: 19972004 e 2005-2011, identificando os quatro tipos de clusters de agrupamento padrão alto-alto.

Os resultados da Análise Exploratória de Dados Espaciais (AEDE) permitiu verificar que ocorreu significativa redução do cluster baixo-baixo principalmente de municípios pertencentes à mesorregião Centro Sul a partir do ano de 2005. A Figura 5 permite visualizar que a mesorregião Oeste obteve uma melhora significativa nas receitas oriundas do

\footnotetext{
${ }^{47}$ Valores corrigidos pelo IPC-A a preços de 2011.
} 
Imposto sobre Propriedade Predial e Territorial Urbana (IPTU), mesmo sendo em níveis muito inferior quando comparadas à mesorregião Metropolitana de Curitiba e Norte Central. O que se pode concluir é que está ocorrendo uma desaceleração dessas receitas mesmo que a mesorregião Metropolitana de Curitiba correspondeu, em 2011, por mais de 50\% dessas receitas no estado.

Fica evidente que a mesorregião Metropolitana de Curitiba no período correspondente a 2005-2011 não se mostrou ser mais eficiente nas arrecadações do Imposto sobre Propriedade Predial e Territorial Urbana (IPTU) que às demais mesorregiões do estado. Isso pode ter ocorrido em virtude dos municípios menores terem o Imposto sobre Propriedade Predial e Territorial Urbana (IPTU) como único instrumento de alavancar suas receitas para atender suas demandas por bens e serviços públicos após a efetiva implementação da Lei de Responsabilidade Fiscal (LRF).

Dessa forma, a mesorregião Metropolitana de Curitiba não mostrou ser mais eficiente na arrecadação dos impostos típicos de municípios no segundo período em relação ao primeiro. Todavia, mesmo estando ocorrendo uma desaceleração nas taxas de crescimentos das receitas do Imposto sobre Propriedade Predial e Territorial Urbana (IPTU) no segundo período ainda observa-se altamente concentrado na mesorregião Metropolitana de Curitiba. Vale ressaltar que o Imposto sobre Propriedade Predial e Territorial Urbana (IPTU) pode ser um instrumento de grande relevância para melhorar as contas públicas dos menores munícipios e garantir serviços de melhor qualidade à população.

Para evitar polêmicas em relação à atualização da Planta Genérica de Valores que os gestores e legisladores municipais insistem em não fazer em virtude do desgaste que isto acarreta em suas carreiras políticas, sugere-se uma Proposta de Emenda Constitucional (PEC) no art. 156 que torne obrigatória a atualização da Planta Genérica de Valores dos imóveis em um período mínimo de quatro anos. Também, recomenda-se que inclua no $\S 1^{\circ}$ do art. 14 da Lei 101/2000 (LRF) como renúncia fiscal a inércia de não atualizar a Planta Genérica de Valores. Dessa forma, mesmo aumentando a carga tributária os municípios podem diminuir sua dependência das receitas vinculadas da União no que se refere aos recursos financeiros que garante principalmente aos serviços de saúde e educação. Ainda, podem-se destinar recursos para investimentos, os quais no Brasil representa apenas um terço do total dos investimentos público do País que são realizados pelos estados confederados e municípios. Diferente dos países pertencentes à Organização de Cooperação e de Desenvolvimento Econômico (OCDE) onde esses entes são responsáveis por dois terços dos investimentos públicos. 
Ressalta-se que as avaliações sobre o tema não foram esgotadas neste artigo e outros estudos devem ser realizados para o real entendimento sobre a tributação do Imposto sobre Propriedade Predial e Territorial Urbana (IPTU). Estudos que comparem o comportamento do Imposto sobre Propriedade Predial e Territorial Urbana (IPTU) com os demais impostos de competência municipal podem ajudar a entender sua dinâmica. Portanto, com este estudo espera ter contribuído para um melhor entendimento da temática abordada.

\section{REFERÊNCIAS BIBLIOGRÁFICAS}

AFONSO, J.R.R. Papel da Renúncia na Competitividade da Economia. In: SEMINÁRIO GOVERNANÇA E RENÚNCIA TRIBUTÁRIA, 1., 2013, Brasília. Anais... Brasília: Plenário do Tribunal de Contas da União, 2013.

ALMEIDA, E. Curso de Econometria Espacial Aplicada. Piracicaba: ESALQ-USP, 2004.

ANDRADE, N.A. Contabilidade Pública na Gestão Municipal. São Paulo: Atlas, 2002.

Planejamento Governamental para Municípios. São Paulo: Atlas, 2006.

ANSELIN, L. Exploring spatial data with geode: a workbook. University of Illinois, Urbana-Champaing. 2005. Disponível em: <https://geodacenter.asu.edu/system/ files/GeodeWorkbook. Pdf >. Acesso em: 11 nov. 2012.

ATALIBA, G. Hipótese de Incidência Tributária. 5. ed. São Paulo: Malheiros, 1996.

BARRETO, A.F. Curso de Direito Tributário Municipal. São Paulo: Editora Saraiva, 2009.

BRASIL. Código Tributário Nacional. São Paulo: Revista dos Tribunais, 2003.

BRASIL. Código Tributário Nacional. Organização dos textos de Humberto Castello Branco; Octavio Bulhões; Carlos Medeiros Silva. 2003. Disponível em < http://www.normaslegais.com.br/legislacao/lei5172-1966-codigo-tributario-nacionalctn.htm>. Acesso em: 02 nov. 2013.

BRASIL. Ministério da Fazenda. Secretaria do Tesouro Nacional. 2012. Disponível em: <http://www.receita.fazenda.gov.br>. Acesso em: 23 out. 2012.

CUNHA, A.S. Série de Testos para Discussão: Os impostos e a História. Brasília: [s.n], 2002.

DANTAS, P.R. de F. Direito Constitucional. 7. ed. São Paulo: Atlas, 2011.

DI PIETRO, M.S.Z. Direito Administrativo. 12. ed. São Paulo: Atlas, 2000. 
DIAS, M.A. James Buchanan e a "Política" na Escolha Pública. Ponto-e-vírgula, 6: 201217, 2009. Disponivel em: < http://www.normaslegais.com.br/legislacao/lei5172-1966codigo-tributario-nacional-ctn.htm>. Acesso em: 14 março de 2013.

Giambiagi, F.; AlÉM, A. C. Finanças Públicas: Teoria e Prática no Brasil. Rio de Janeiro: Campus, 2000.

IPARDES - Instituto Paranaense de desenvolvimento econômico e social. Mapas. 2012. Disponível em: < http://www.ipardes.gov.br/index.php?pg_conteudo=1\&cod_conteudo=45>. Acesso em: 01 nov.2013.

LINO, P. Comentários à Lei de Responsabilidade Fiscal. São Paulo: Atlas, 2001.

MACHADO, H. B. Curso de direito tributário. 20. ed. Rio de Janeiro: Forense 2001.

MARTINS, I.G. da S. M.; PEIXOTO, M.M. ISS - LC 116/2003. Curitiba: Juruá, 2008.

NUNES, S.P.P. Impacto na Gestão Fiscal: perspectiva de controle da renúncia da receita. In: SEMINÁRIO GOVERNANÇA E RENUNCIA TRIBUTÁRIA. 1., 2013, Brasília. Anais... Brasília: Plenário do Tribunal de Contas da União, 2013.

OLIVEIRA, J.J. M. Impostos Municipais: ISS, IPTU, ITBI. São Paulo: Saraiva, 2009.

PARANÁ. Instituto Paranaense de Desenvolvimento Econômico - IPARDES. 2013. Disponível em: <http://www.ipardes.gov.br>. Acesso em: 13 mar. 2013.

PEROBELLI, F. S.; FERREIRA, P. G. C. ; ALMEIDA, E. S. Existe convergência espacial da produtividade agrícola no Brasil? RER, Rio de Janeiro, v. 46, n. 1, p. 31-52, jan/mar 2008. Disponível em: < http://www.scielo.br/pdf/resr/v46n1/a02v46n1.pdf>. Acesso em: 10 nov. 2013.

PIMENTEL, E.; HADDAD, E. A. Análise da distribuição espacial da renda no estado de Minas Gerais: Uma abordagem setorial. São Paulo: NEREUS - FEA-USP, 2004.

PINDYCK, R.S; RUBINFELD, D.L. Microeconomia. São Paulo: Pearson Prentice Hall, 2006.

PRADO JUNIOR, C. História Econômica do Brasil. São Paulo: Brasilense, 2004

RIANI, F. Economia do Setor Público: Uma Abordagem Introdutória. 3. ed. São Paulo: Atlas, 1997.

RIBEIRO, E.C.B.A. Convergência de renda local entre os municípios brasileiros para o período 2000 a 2005. 2010. 210 f. Dissertação (Mestrado em Economia) - Faculdade de Economia da Universidade Federal de Juiz de Fora, Juiz de Fora, 2010.

SANTOS, R. G.. et al. Análise espacial da arrecadação de impostos típicos de municípios no período de 2000 a 2011 no estado do Paraná. In: ENCONTRO DE ECONOMIA CATARINENSE, 7., 2013, Florianópolis. Anais... Florianópolis, 2013. Disponível em: < http://www.apec.unesc.net/VII_EEC/sessoes_tematicas/\%C3\%81rea 
\%202\%20Fin\%20Publicas/AN\%C3\%81LISE\%20ESPACIAL\%20DA\%20ARRECADA\%C3 \%87\%C3\%83O\%20DE\%20IMPOSTOS.pdf>. Acesso em: 01 nov. 2013.

SPITZCOVSKY, C.; MOTA, L.P. Direito Constitucional. 9. ed. Rio de janeiro: Forense, 2008.

TEIXEIRA, R.F.A.P. et al. Produtividade e logística na produção do biodiesel. Ensaios FEE, Porto Alegre v. 31, n. 1, p. 7-30, ago. 2010. Disponível em: < https://www.google.com.br/url?sa=t\&rct=j\&q=\&esrc=s\&source=web\&cd=1\&ved=0CC0QFj AA\&url=http $\% 3 \mathrm{~A} \% 2 \mathrm{~F} \% 2$ Frevistas.fee.tche.br\%2Findex.php $\% 2$ Fensaios $\% 2$ Farticle $\% 2 F d o w$ nload\%2F2213\%2F2731\&ei=MQ2CUpzXIvXH4AO1 y4DYCA\&usg=AFQjCNGV5aTPW60qNDHvTLMWfwlistEA\&sig2=DwLyy1IDFT3u4eZqqi2PpA\&bvm=bv.56146854, d.dmg>. Acesso em: 10 nov. 2013.

VILLELA, L.A. Gastos Tributários Experiência Internacional. In: SEMINÁRIO GOVERNANÇA E RENUNCIA TRIBUTÁRIA. 1., 2013, Brasília. Anais... Brasília: Plenário do Tribunal de Contas da União, 2013. 